\title{
Long-Term Follow-Up of
} Intravitreal Bevacizumab in Retinal Arterial Macroaneurysm: A Case Report

\author{
Shani Golan ${ }^{a, b}$ Daphna Goldenberg ${ }^{a, b}$ \\ Michaella Goldstein ${ }^{a, b}$ \\ ${ }^{a}$ Department of Ophthalmology, Tel Aviv Sourasky Medical Center, and \\ ${ }^{\mathrm{b}}$ Sackler Faculty of Medicine, Tel Aviv University, Tel-Aviv, Israel
}

\section{Key Words}

Bevacizumab (Avastin ${ }^{\circledR}$ ) $\cdot$ Retinal macroaneurysm · Anti-VEGF therapy $\cdot$ Macular edema

\begin{abstract}
Purpose: To present the long-term effect of intravitreal bevacizumab (Avastin ${ }^{\circledR}$ ) therapy in a patient suffering from retinal arterial macroaneurysm.

Methods: Case report of a 72-year-old female diagnosed with retinal macroaneurysm in the superior temporal artery leading to macular edema. Functional and morphological data at baseline, 4 weeks, 2 months, and 13 months following treatment with two consecutive intravitreal bevacizumab injections are presented.

Results: Best-corrected visual acuity improved from 20/160 at baseline to 20/20 at the 3-months follow-up and remained stable through 13 months of follow-up. Central retinal thickness measured by optical coherence tomography decreased from $364 \mu \mathrm{m}$ at baseline to $248 \mu \mathrm{m}$ at the 13-months follow-up. No ocular or systemic side effects were detected. Conclusions: Intravitreal bevacizumab therapy may lead to resolution of macular edema associated with retinal macroaneurysm and consequently visual improvement. This treatment may promise a long-lasting effect but warrant further investigation in larger series.
\end{abstract}

\section{Case Report}

A 72-year-old female patient with hypertension and diabetes presented with visual disturbance OD. Best-corrected visual acuity (BCVA) was 20/160 OD and 20/20 OS. In both eyes, anterior segment examination was unremarkable. Funduscopy OD showed subretinal fluid and retinal hemorrhage in the superior temporal arcade with associated macular edema (ME), and few small intraretinal hemorrhages inferior to the macula, with no ME OS (ig. 1a). 
Based on fluorescein angiography and indocyanine green, the diagnosis of leaking retinal macroaneurysm OD and inactive macroaneurysm + mild nonproliferative diabetic retinopathy OS was confirmed (fig. 1b-e). Central retinal thickness (CRT) OD was measured by optical coherence tomography (OCT, SD-OCT Cirrus, Zeiss) as $364 \mu \mathrm{m}$ (fig. 1f).

Due to the location of the macroaneurysm OD, direct laser therapy was omitted in fear of closing the artery. After written consent for off-label use of intravitreal bevacizumab (Avastin ${ }^{\circledR}$ ) was obtained, an injection $(1.25 \mathrm{mg}$ in $0.05 \mathrm{ml}$ ) was applied to the patient's right eye.

At 4 weeks following the injection, BCVA OD improved to 20/32. Retinal hemorrhage was reduced and CRT decreased to $328 \mu \mathrm{m}$. However, the hard exudates were more prominent. A second bevacizumab injection was performed 4 weeks after the first one. Four weeks after the second injection, the retinal hemorrhages and ME almost completely resolved ( $\underline{\text { fig. } 2 \mathrm{a}}$ ).Three months following the first injection, the ME had completely resolved, BVCA improved to 20/20 and CRT was $242 \mu \mathrm{m}$. These findings remained stable after 6 and 13 months (fig. $2 \mathrm{~b}$ ) of follow-up.

\section{Discussion}

Acquired retinal macroaneurysms are localized fusiform or round dilatations of retinal arterial branches [1,2]. Current treatment options include observation and direct laser coagulation $[3,4]$. The use of intravitreal injection of vascular endothelial growth factor (VEGF) inhibitors, such as ranibizumab or bevacizumab, is an effective treatment modality in neovascular age-related macular degeneration [5], ME due to diabetes $[6,7]$ or vein occlusion [8].

Focal embolic damage to arterial walls is thought to cause retinal macroaneurysm. As a result, localized ischemia with VEGF-associated increased permeability and dilatation of the artery occurs and causes ME and hard exudates [2]. Anti-VEGF drugs can prevent the formation of abnormal blood vessels and counteract VEGF-induced vascular permeability. They might actively close the involved permeabilized retinal artery and normalize the vessel wall by localized inhibition of VEGF. So far, there are only 3 reports on retinal macroaneurysm treated with intravitreal bevacizumab $[9,10]$. After a follow-up of 6 weeks to 8 months, BCVA increased in all patients, and no adverse effects were observed.

In our patient, following the bevacizumab injection there was a reduction of ME with visual improvement, lasting 13 months. The therapy was well tolerated without adverse events. The observed beneficial effect of anti-VEGF therapy in macroaneurysms warrant further investigation. This treatment option should be considered when laser therapy is inappropriate or not working, or in patients in whom there is evidence of extensive ME.

\section{Disclosure Statement}

The authors have no financial support and no proprietary interest. 

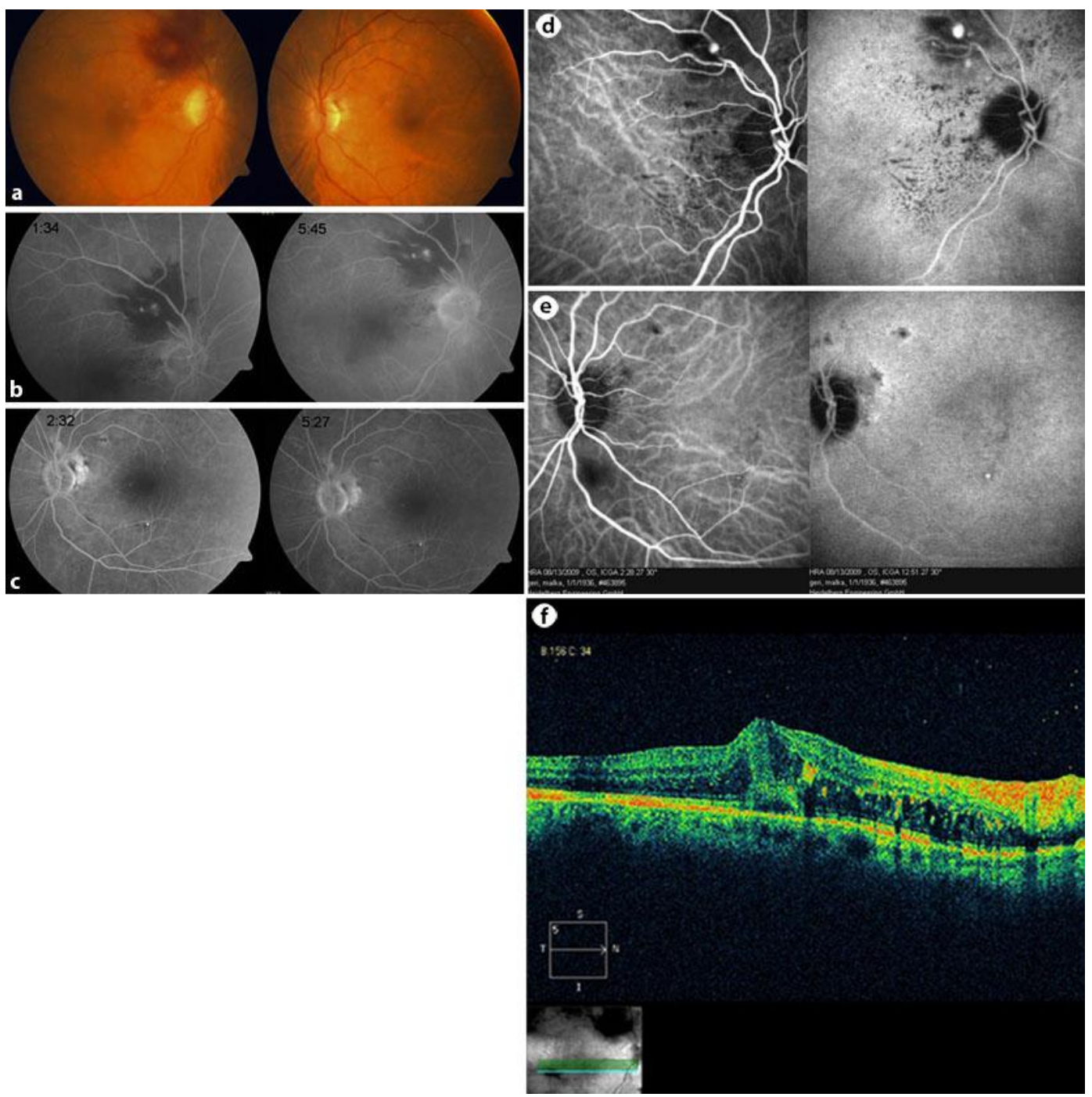

Fig. 1. a Fundus examination of the right eye showed subretinal fluid and retinal hemorrhage in the superior temporal arcade with associated macular edema, and normal attached peripheral retina. In the left eye, few small intraretinal hemorrhages inferior to the macula, flat macula with no edema and normal attached peripheral retina were identified. b, c Fluorescein angiogram showing a

hyperfluorescent spot with late leakage consisted with macroaneurysm within a larger area of blocked hypofluorescence OD (b) and a small retinal macroaneurysm OS (c). d, e Indocyanine green nicely demonstrates the superotemporal macroaneurysm OD (d) and the inferotemporal macroaneurysm OS (e). f Pre-treatment OCT (SD-OCT Cirrus by Zeiss) demonstrates subretinal fluids, originating from the macroaneurysm with associated subfoveal fluid, retinal edema and intraretinal lipids. CRT OD is $364 \mu \mathrm{m}$. 

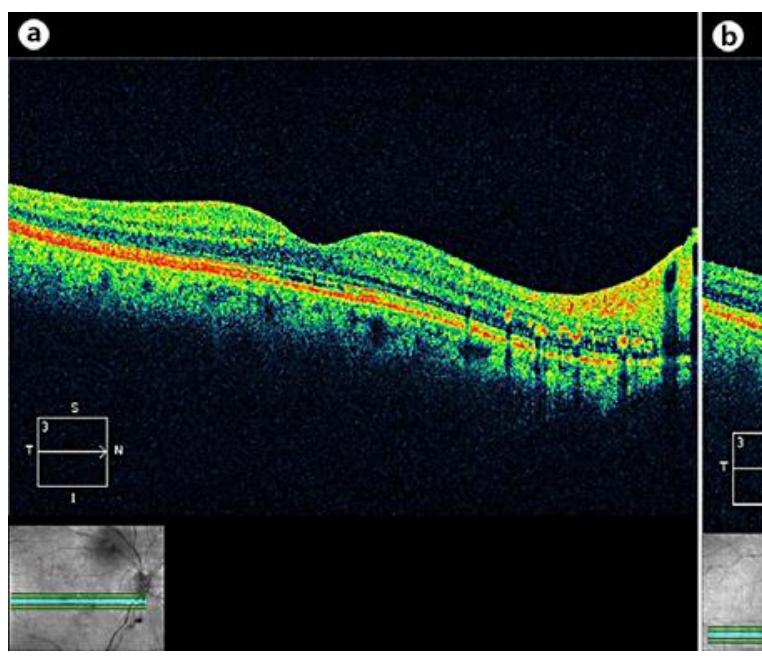

Fig. 2. a OCT performed 1 month following 2 IVT bevacizumab injections demonstrating normal foveal contour OD, complete resolution of subretinal and intraretinal fluids. Note the disappearance of the previously seen intraretinal lipids. b OCT performed at the last follow-up visit, 13 months following 2 IVT bevacizumab injections demonstrating stable, normal foveal contour, and a CRT of $248 \mu \mathrm{m}$. 


\section{References}

1 Chew EY, Murphy RP: Acquired retinal macroaneurysms; in Ryan SJ (ed): Retina. Vol 2; Medical Retina. St. Louis, Mosby, 2005, pp 1499-1502.

-2 Lewis RA, Norton EW, Gass JD: Acquired arterial macroaneurysms of the retina. Br J Ophthalmol 1976;60:21-30.

-3 Tsujikawa A, Sakamoto A, Ota M, Oh H, Miyamoto K, Kita M, Yoshimura N: Retinal structural changes associated with retinal arterial macroaneurysm examined with optical coherence tomography. Retina 2009;29:782-792.

4 Brown DM, Sobol WM, Folk JC, Weingeist TA: Retinal arteriolar macroaneurysms: long-term visual outcomes. Br J Ophthalmol 1994;78:534-538.

5 Rosenfeld PJ, Brown DM, Heier JS, Boyer DS, Kaiser PK, Chung CY, Kim RY, Marina Study Group: Ranibizumab for neovascular age-related macular degeneration. N Engl J Med 2006;355:1419-1431.

-6 Chun DW, Heier JS, Topping TM, Duker JS, Bankert JM: A pilot study of multiple intravitreal injections of ranibizumab in patients with center-involving clinically significant diabetic macular edema. Ophthalmology 2006;113:1706-1712.

>7 Diabetic Retinopathy Clinical Research Network, Elman MJ, Aiello LP, Beck RW, et al: Randomized trial evaluating ranibizumab plus prompt or deferred laser or triamcinolone plus prompt laser for diabetic macular edema. Ophthalmology 2010;117:1064-1077.

8 Pieramici DF, Rabena M, Castellarin AA, et al: Ranibizumab for the treatment of macular edema associated with perfused central retinal vein occlusions. Ophthalmology 2008; 115:47-54.

9 Chanana B, Azad RV: Intravitreal bevacizumab for macular edema secondary to retinal macroaneurysm. Eye 2009;23:493-494.

10 Jonas JB, Schmidbauer M: Intravitreal bevacizumab for retinal macroaneurysm. Acta Ophthalmol 2010;88:e284 